\title{
The Effect of State and Local Government Employment on Income in Metropolitan Areas
}

\author{
Robert C. Posatko and Jacob De Rooy*
}

\section{INTRODUCTION}

The conventional approach to the question of public sector impact on a region's economy is to focus on public investment as a causal force behind economic growth and development. ${ }^{1}$ The purpose of this paper is to investigate the impact of another, relatively neglected aspect of public sector activity on local economic well-being. This paper is focused on public sector employment as a determinant of the level of regional income. More specifically, our objective is to identify the relationship between non-federal government employment and wage incomes within a region, and to examine for differentials in this relationship among areas which vary in size (population). The results generated provide evidence on the role of government employment as an instrument for regional development. The paper would also assist in appraising the potential effects on a local economy of significant reductions in public sector employment, such as would result from mandated tax cuts, or from other government spending constraints.

The unit of observation in this analysis is the standard Metropolitan Statistical Area (SMSA). The data base for our empirical analysis relates to economic and demographic variables for the 246 SMSA's within the U.S. in 1970. All of the data are contained in the 1972 COUNTY AND CITY DATA BOOK. ${ }^{2}$ Following the theoretical model presented in Section II, which specifies the relationship between government employment and regional income, Section III presents and discusses the preliminary twostage least squares estimates of the area income effect of government employment. Regression analysis is employed to estimate both the primary and secondary impacts of public employment on wage income. The concluding section discusses the effects of adjustments made to the model for region size.

\section{PUBLIC EMPLOYMENT AND INCOME}

The term government employment as used below refers to public sector jobs at the two lower levels of government, namely, the state and local levels. Our analysis is limited to non-federal employment for several rea- 
sons. It is apparent that important differences exist in the nature and function of government employment between the federal level and these two lower levels. For example, Federal employees do not participate in the operation and maintenance of highways and bridges, in traffic control or education, in trash collection or snow removal. On the other hand, state and local employees do not manage army ordnance or service Veterans Administration claims. In general, non-federal employment generates more locally identifiable benefits, while federal activities tend to have a broader spatial impact. There are differences also in wage rates among the levels of government, with higher pay scales realized typically by federal workers. For these reasons, the impact of public employment on local income might be expected to vary according to the level of government involved. Ideally, it would be desirable to disaggregate public sector employment by each of the three levels of government. It would also be desirable to account for the jurisdictional incidence of the tax or debt burden created to finance the government employment. We would expect, for example, that any negative tax impact (tax "friction") of financing increments in federal employment on a given region will be smaller than that involving state employment because the tax cost of the former is spread over a broader (national) tax base. Similarly, the negative tax impact of state employment on a locality is likely to be less than that of local (county/municipal) employment. ${ }^{3}$

While data limitations preclude a complete disaggregation into federal, state and local employment, we are able to separate out the number of federal workers in each SMSA. ${ }^{4}$ This allows us to investigate the economic impact of combined state-local public employment on a region. The analysis also permits us to examine directly the implications of the various initiatives for state and local fiscal constraint spawned by California's Proposition 13.

Analogous to a standard microeconomic production function relevant to a firm, a production function of a regional nature can be constructed. ${ }^{5}$ Thus, for SMSA's we specify the production relationship

$$
Q_{j}=f\left(E M P_{j}, C A A P_{j}, L A N D_{j}\right)
$$

where $Q_{j}$ is the aggregate output of the $\mathrm{j}$-th area, $\mathrm{EMP}_{\mathrm{j}}$ is the total employment in the area, CAP ${ }_{j}$ is the area's capital stock and $\mathrm{LAND}_{\mathrm{j}}$ is its land resources. Total employment of labor in a region is determined by an aggregate derived demand function for labor services in the region

(2) $\mathrm{EMP}_{\mathrm{j}}=\mathrm{f}\left(\mathrm{Q}_{\mathrm{j}}, \mathrm{W}_{\mathrm{j}} / \mathrm{P}_{\mathrm{j}}\right)$,

where regional output $Q_{j}$ is given by equation (1), and $W_{j} / P_{j}$ is the average real wage rate in the region. $\left(\mathrm{W}_{\mathrm{j}}\right.$ is the average money wage rate in region $\mathrm{j}$, while $P_{j}$ is the $j$-th region price level.) This function is similar to the specifications of employment equations in a large number of regional econometric models, such as that for the state of Mississippi by Adams et $a l .{ }^{6}$ The region's real wage rate in equation (2) is dependent on the quality 
of the labor force, relating to past investment in its human capital $\mathrm{ED}_{\mathrm{j}}$, the level of surplus labor in the regional labor market $U N E M P_{j}$, and the stock of capital in the region with which labor services are combined $\operatorname{CAP}_{j}$. Expressed more formally, this relationship is written as

(3) $\quad W_{j} / P_{j}=f\left(E_{j}, U D P_{j}, C A A P_{j}\right)$

The product of total employment and the real wage rate gives the aggregate real wage income $W_{\mathrm{j}}$ in area $\mathrm{j}$

(4) $\mathrm{WI}_{\mathrm{j}} \equiv \mathrm{EMP}_{\mathrm{j}} .\left(\mathrm{W}_{\mathrm{j}} / \mathrm{P}_{\mathrm{j}}\right)$

Substituting equation (3) into (4) results in

(5) $\mathrm{WI}_{\mathrm{j}}=\mathrm{f}\left(\mathrm{EMP}_{\mathrm{j}}, \mathrm{ED}_{\mathrm{j}}, \mathrm{UNEMP}_{\mathrm{j}}, \mathrm{CAP}_{\mathrm{j}}\right)$

Equation (5) thus expresses wage income in a region as a function of the number of workers in the region, their average quality or skill level, the quantity of surplus labor in the area and the capital stock utilized by labor.

Aggregate regional employment, represented as $\mathrm{EMP}_{\mathrm{j}}$ in the above equations, is the sum of private and public sector components

(6) $\mathrm{EMP}_{\mathrm{j}} \equiv \mathrm{EMP}_{\mathrm{j}}^{(\mathrm{p})}+\mathrm{EMP}_{\mathrm{j}}^{(\mathrm{g})}$

where superscripts $\mathrm{p}$ and $\mathrm{g}$ respectively denote private sector and public sector (state and local) within the region. Federal employment is not of special interest in our analysis, and is a comparatively small component of the employment total for most areas. Thus, we shall include it in the private sector total.

Analogous to aggregate labor demand in equation (2), the private sector labor demand function is expressed as

(7) $\operatorname{EMP}_{j}{ }^{(p)}=f\left(Q_{j}^{(p)}, W_{j}^{(p)} / P_{j}\right)$,

where $\operatorname{EMP}_{j}{ }^{(p)}$ is the number of jobs in the private sector, $Q_{j}{ }^{(p)}$ is the region's total private sector output, and $W_{j}{ }^{(p)} / P_{j}$ is the real wage rate in the private sector. From equation (6) it follows:

(8) $E M P_{j}=f\left(Q_{j}^{(p)}, W_{j}^{(p)} / P_{j}, E M P_{j}^{(g)}\right)$

Turning now to the employment equation for the non-federal public sector, it may be noted that non-federal government services, as do services in other sectors, require the input of both labor and capital ("infrastructure"). Our focus in the present work is on the labor component in government services. Public employment is viewed as a direct indicator of the level of government services produced. Several recent works have studied the demand for non-federal services. ${ }^{7}$ These analyses develop demand relationships for specific individual services, such as education, 
police and fire protection and recreation. Each identifies a region's income level as a significant determinant of the public service levels it demands. Our model also specifies aggregate regional income $Y_{j}$ in the government services (government employment) function. Additional variables which appear in previous studies as well as in our model are intergovernmental transfers to the region $T R_{j}$, the real wage rate of non-federal workers in the region $W_{j}{ }^{(g)} / P_{j}$, institutional factors unique to the area, and the structural makeup of the region's economy $\mathrm{ES}_{\mathrm{j}}$. Thus,

$$
\text { (9) } \mathrm{EMP}_{\mathrm{j}}^{(\mathrm{g})}=\mathrm{f}\left(\mathrm{Y}_{\mathbf{j}}, \mathrm{TR}_{\mathrm{j}}, \mathrm{W}_{\mathrm{j}}^{(\mathrm{g})} / \mathrm{P}_{\mathrm{j}}, \mathrm{I}_{\mathrm{j}}, \mathrm{ES}_{\mathrm{j}}\right)
$$

Transfers from other governments received by the region serve to reduce the cost of services that must be borne by the benefitted area. Matching grants programs and outright general purpose revenues constitute the major forms of intergovernmental transfers. Matching grants stimulate the demand for specific public services and investments. Revenue sharing funds, not linked to specific items, tent to increase the demand for a broad range of services and investments. In either form, the amount of transfers received by a unit of government is expected to be positively related to the level of services it provides. Similar to the demand for labor generally, the real wage rate of employees in the public sector is likely to exert a negative influence on the number of individuals employed in the production of public services. Institutional factors include the set of historical and political determinants of the location of government agencies, in particular, those state installations that need not be located near all the people they serve. Finally, the composition of a region's economic activity has a bearing upon the scope and level of government services needed to complement that activity. Heavy manufacturing, for example, may require a larger number of transportation and traffic control employees in the public sector than do the generation of revenues in insurance or education.

Aggregate regional income $\mathrm{Y}_{\mathbf{j}}$ is composed of a total wage income component $\mathrm{WI}_{\mathrm{j}}$ and a total property income component $\mathrm{PI}_{\mathrm{j}}$. Thus,

$$
\mathrm{Y}_{\mathrm{j}} \equiv \mathrm{WI}_{\mathrm{j}}+\mathrm{PI}_{\mathrm{j}}
$$

By substituting equation (10) for $Y_{j}$, equation (9) is re-written as

$$
\text { (11) } \mathrm{EMP}_{\mathrm{j}}{ }^{(\mathrm{g})}=\mathrm{f}\left(\mathrm{WI}_{\mathrm{j}}, \mathrm{PI}_{\mathrm{j}}, \mathrm{TR}_{\mathrm{j}}, \mathrm{W}_{\mathrm{j}}^{(\mathrm{g})} / \mathrm{P}_{\mathrm{j}}, \mathrm{I}_{\mathrm{j}}, \mathrm{ES}_{\mathrm{j}}\right)
$$

Property income receipts of the residents of an area are dependent on the amounts of, and rates of return to, the capital and land resources owned by the area's residents. Stated more formally,

$$
P I_{j}=f\left(C A P, r, r_{j}, L_{A N D}, h_{j}\right)
$$

where $r_{j}$ is the annual rate of return to capital resources, and $h_{j}$ is the comparable rate of return to land resources.

Given the above system of equations, our focus on state and local gov- 
ernment employment indicates, via equation (8), that total employment in a region is a function of $\mathrm{EMP}_{\mathrm{j}}{ }^{(\mathrm{g})}$. A change in total employment, however, through equation (5), affects regional wage income $\mathrm{WI}_{\mathbf{j}}$. In turn, a change in wage incomes impacts, through equation (11), on the size of the nonfederal workforce. In short, simultaneity exists between government employment and area income. Our model accounts for this by treating government employment as an endogenous variable that is a function of aggregate income as well as other variables.

Equations (1), (5), (8), (11) and (12) are the structural equations of the model. In the empirical analysis in Section III our attention will focus on the last four of these equations. Structural equation (1) was not estimated since, as is the case for other regional econometric models, data were not available for estimating the parameters of a regional production function. Within the group of structural equations to be estimated, therefore, aggregate regional output $Q_{\mathrm{j}}$ is treated as exogenous. However, this group of 4 structural equations precludes any secondary effect of government employment on locally generated income. This secondary effect arises from induced spending (and hence output) in the region due to the income increases associated with additional government employment.

In an effort to more fully incorporate the secondary impact of public employment on income, an additional equation representing local sales is introduced into the existing 4 -equation system. For most regions, total area output is sold partly in an "export" market outside the area itself, and partly to its own residents, or

$$
Q_{j} \equiv Q_{j}^{(e)}+Q_{j}^{(j)},
$$

where superscripts e and j respectively denote external and local sales sources. The locally purchased output will be dependent on the region's income level, and presumably other factors such as tastes and preferences for the area's output mix, demographic factors, and degree of import substitution achieved by the area. Expressed more formally,

$$
Q_{j}^{(j)}=f\left(W I_{j}, P I_{j}, A G E_{j}, D^{(c)}\right),
$$

where $\mathrm{AGE}_{\mathrm{j}}$ is the median age of the local population, an important determinant of aggregate consumption, and $\mathrm{D}^{(\mathrm{c})}$ is the percentage of the region's workforce which commutes out of the area for employment.

Inclusion of equation (14) along with equations (5), (8), (11) and (12) permits us to take account of the secondary effect of government on local sales, and hence, employment and income. Estimation of equation (14) simultaneously with the first four equations serves to treat the area's locally-purchased output as endogenous. We are, therefore, able to capture more fully the impact of state and local government employment on a region's total employment and income. 


\section{THE AREA INCOME EFFECT: PRELIMINARY ESTIMATES}

Parameter estimates of the structural equations (5), (8), (11), (12), and (14) were obtained by using 1972 cross-section data for SMSA's in the United States. We are primarily interested here in the estimates of the coefficient of public sector (non-federal) employment in the total employment equation and in the coefficient of total employment in the wage income equation. The product of these two coefficients is the area income effect of public employment (AIE). The AIE is defined as the incremental wage income generated by the addition of one unit of public sector employment. Two estimates of AIE are reported in this section. The first is derived from the simultaneous estimation of the wage income, total employment, public sector employment, and property income equations only. By excluding the sales equation, private sector output is held constant and the AIE measures the primary impact of public sector employment on wage income, assuming that wage income resulting from public sector employment does not induce indigenous private sector activity. ${ }^{8}$ The second estimate of the AIE is derived from the simultaneous estimation of parameters of all five equations, including the sales equation (14). This sub-system treats a substantial indicator of regional output (retail sales) as endogenous so that we can observe the induced effects occasioned by the increased demand for local goods and services of public sector employees. We would expect this total (primary and secondary) AIE to be larger than that derived from the coefficients of the four-equation sub-system. The difference between these two estimates of the AIE may be interpreted as a measure of the secondary, or induced, impact of public employment on the private sector, although our estimates of the total and secondary impacts will be biased downward due to the exclusion of some regional output.

Use of the SMSA as the unit of observation is appropriate for this study because the cluster of counties comprising an SMSA is based largely on worker commuting patterns, so the SMSA coincides with the labor market. ${ }^{9}$ In addition, the SMSA is the most widely employed delineation of geographic regions utilized in empirical work.

Econometricians have generally assumed that cross-section models describe changes in comparative statics, without measuring the time path between equilibria. Thus, the model in our analysis may be interpreted as describing the changes in spatial equilibria, or "long-run" adjustments. arising from changes in the size of the non-federal public sector work force.

Parameter estimates used in this study were obtained from the two-stage least squares (TSLS) estimator. ${ }^{10}$ Such estimates have been shown to be biased but consistent for large samples, such as the sample of 246 SMSA's used here. ${ }^{11}$ The relative efficiency of TSLS regression estimates can be determined by their t-ratios (parameter estimate divided by TSLS estimate of the standard error of the parameter's sampling distribution). For large samples coefficient estimates are significantly different from zero at the 0.05 level if their t-ratios are at least as large as 1.96 , and are significant at the 0.01 level if their t-ratios exceed 2.57. 
An important adjustment was made to all monetary variables. While the use of cross-section data avoids the problem of inflationary distortions over time, important inter-regional differences in price levels affect comparisons of monetary measures. Therefore, all monetary variables were adjusted by an urban area price deflator, or metropolitan "cost of living" index, reported for each SMSA by Liu. ${ }^{12}$ Thus, all monetary variables are expressed in real terms.

The TSLS estimates of the structural equations in the four-equation sub-system are presented in the top half of Table 1 . The regressand is real gross personal income from wages and salaries (WI). ${ }^{13}$ The regressor of greatest importance for our analysis is total public and private sector employment (EMP), with a coefficient of $7.235 \times 10^{-3}$, or $\$ 7,235$ per employee, which is the marginal wage of an additional worker averaging over the two sectors. Education preparation $(\mathrm{ED})$ is measured by the mean number of years of schooling completed by persons 25 years old or older. The unemployment rate (UNEMP), expressed as a percentage, was used to indicate labor surplus. From the wage rate equation (3), we anticipated a negative sign, which would have suggested that the existence of a labor surplus depressed local wage rates. However, the coefficient is highly significant and positive. This suggests that regions with high wage rates attract many job seekers who might not be qualified for, or are excluded from, well-paying jobs and who increase the size of the labor surplus.

Following equation (8), total regional employment is specified as a function of regional output, the wage rate, and public sector employment. We used two measures of regional output. The first is value-added in manufacturing $\left(Q^{(m)}\right)$, and the second is retail sales $\left(Q^{(s)}\right)$. The major output measures not included cover services. Service receipts were excluded from the final version of the model because in earlier specifications, where it was included, multicollinearity resulted in nonsignificant parameter estimates. The regional wage rate is represented by the mean hourly wage of production workers in manufacturing, $\mathrm{W} / \mathrm{P}^{(\mathrm{m})}$. A broader indicator of regional wage rates would have been desirable. However, since manufacturing firms compete with other local employers for labor, there is likely to be a high correlation across SMSA's between wages in manufacturing and wages in other industries. As expected, the wage rate has a negative sign, which indicates a conventional downward sloping demand curve for labor services. The coefficient of public sector employment, $\mathrm{EMP}^{(\mathrm{g})}$, is 2.410. This indicates that the long-run effect of adding one person to the public sector work force is the creation of an additional 1.4 jobs, some of which might also be in the public sector. It is noteworthy that this figure is not very different from employment multipliers derived from other econometric labor demand models. ${ }^{14}$

Equation (11) describes the demand for public sector labor services. Non-federal government employment is highly correlated with regional income (WI and PI) and with intergovernmental transfers (TR). Governments generate revenue from taxation of income and taxation of property whose value is related to owners' incomes, and from funds received from other governments. This revenue determines the ability to pay for labor 
TABLE 1.

TSLS Estimates of Structural Equations

[Figures in brackets are t-ratios]

\section{Preliminary Mode]}

Wage income (EQ.5)

$$
\begin{gathered}
\mathrm{WI}=-859.543+7.235 \times 10^{-3} \mathrm{EMP}+51.861 \mathrm{ED}+47.561 \text { UNEMP } \\
{[2.57] \quad[177.79] \quad[1.91] \quad[3.53]}
\end{gathered}
$$

Employment (EG.8)

$$
\begin{aligned}
& \begin{aligned}
\mathrm{EMP}= & 32879.140+2.410 \mathrm{EMP}^{(\mathrm{g})}+1710.018 \mathrm{Q}^{(\mathrm{s})}+21.490 \mathrm{Q}^{(\mathrm{m})} \\
& {[2.78] } \\
{[11.61] } & {[17.01] }
\end{aligned} \\
& \text { - } 14045.400(\mathrm{~W} / \mathrm{P})^{(\mathrm{m})} \\
& {[3.47]}
\end{aligned}
$$

Public Employment (EQ.11)

$$
\begin{aligned}
& \mathrm{EMP}^{(\mathrm{g})}=17293.170+2.004 \mathrm{WI}+58.636 \mathrm{PI}+33.646 \mathrm{TR}+10011.940 \mathrm{I} \\
& {[3.48] \quad[1.81] \quad[7.78] \quad[8.63] \quad[7.83]} \\
& -11.162(\mathrm{~W} / \mathrm{P})^{(\mathbf{g})}-173.508 \mathrm{ES}^{(\mathrm{m})}-795.923 \mathrm{ES}^{(\mathrm{svc})} \\
& {[1.50] \quad[2.85] \quad[3.03]}
\end{aligned}
$$

Property income (EQ. 12)

$$
\begin{aligned}
& \mathrm{PI}=58.536+0.063 \mathrm{DEP}+0.557 \mathrm{RENT}+0.131 \mathrm{WI} \\
& {[2.42][22.97] \quad[2.33] \quad[58.71]}
\end{aligned}
$$

Full Model

Wage income (EQ. 5)

$$
\mathrm{WI}=\frac{-861.621}{[2.57]}+\frac{7.231 \times 10^{-3} \mathrm{EMP}}{[175.69]}+52.129 \mathrm{ED}+47.512 \mathrm{UNEMP}
$$

Employment (EQ.8)

$$
\begin{aligned}
\mathrm{EMP} & =41556.850+4.041 \mathrm{EMP}^{(\mathrm{g})}+720.891 \mathrm{Q}^{(\mathrm{s})}+72.028 \mathrm{Q}^{(\mathrm{m})} \\
& {[2.87] \quad[11.54] } \\
& -16170.100(\mathrm{~W} / \mathrm{P})^{(\mathrm{m})} \\
& {[3.27] }
\end{aligned}
$$

Public Employment (EQ. 11)

$$
\begin{aligned}
& \operatorname{EMP}^{(\mathrm{g})}=17568.22+2.875 \mathrm{WI}+52.047 \mathrm{PI}+35.898 \mathrm{TR}+9850.28 \mathrm{I}
\end{aligned}
$$

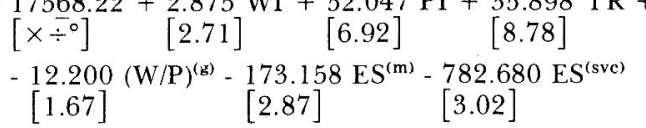

Property Income (EQ. 12)

$$
\begin{aligned}
\mathrm{PI}= & -62.468+0.065 \mathrm{DEP}+0.613 \mathrm{RENT}+0.129 \mathrm{WI} \\
{[2.58] } & {[22.91] } \\
\lfloor 2.55] & \lfloor 55.12\rfloor
\end{aligned}
$$

Sales (EQ. 14)

$$
\left.\mathrm{Q}^{(\mathrm{s})}=-\begin{array}{c}
131.971 \\
{[2.09]}
\end{array}\right]+0.612 \mathrm{WI}-0.529 \mathrm{PI}+7.900 \mathrm{AGE}-4.278 \mathrm{D}^{(\mathrm{c})}
$$


services and plays the same role here as does income in conventional demand functions. The positive sign on each of these variables suggests that government services are "normal goods," with respect to these three sources of government income. The negative sign on the coefficient of the government wage rate $(\mathrm{W} / \mathrm{P})^{(\mathrm{g})}$ indicates a negatively sloped labor demand function. Finally, demand for government employees is determined by regional institutional characteristics and economic structure. The institutional variable is a dummy variable $I$, where $I=1$ if the SMSA contains a state capital (with its concentration of public workers), and 0 otherwise. Economic structure is indicated by the percentage of employed persons engaged in manufacturing, $\mathrm{ES}^{(\mathrm{m})}$, and the percentage engaged in private sector services, $\mathrm{ES}^{(\mathrm{svc})}$.

The final structural equation in this sub-model describes personal income derived from other than wages and salaries, or property income, PI. In lieu of a measure of the value of land resources, the median rent paid for residential units, RENT, is used. Total bank deposits, DEP, is included in the equation as a measure of financial wealth. Bank deposits thus serve as a proxy for the value of the region's capital assets, which is not available for SMSA's. The last variable in the property income equation is WI. This variable indicates the magnitude of the labor input used along with land and capital resources to generate income for owners of these resources.

In order to derive the AIE, the coefficient of government employment in equation (8) is multiplied by the coefficient of total employment in the WI equation $(5)$, or $(2.410)(7.235)=17.436$. This means that the marginal income associated with the addition of one person to the public sector workforce is $\$ 17,436$. The size of this AIE is the result of several distinct effects. The first is the actual annual income received by the public sector employee, and is most likely to be the largest component of the AIE. A second effect is the increased productivity of private sector labor, land, and capital resulting from the additional public services provided. In the long-run, the availability of public services affects location decisions of firms and residents. Thus, new firms will be attracted to the area, existing firms will expand, and the creation of new employment opportunities will draw migrants and raise area income. In short, public services reduce the direct costs, and increase profit margins, of private firms, resulting in a greater demand of firms for land and labor in the SMSA. A third effect is the increased demand for output of the area. The new income received by public sector workers, and by employees of firms which expand in or are drawn to the area, will result in an increase in expenditures for consumer goods and services. If the area is large, it will offer consumers a wide variety of goods and services and a large portion of the new purchases will be made locally. However, even if receivers of new income import goods and services from other areas, the new income of these areas may serve to increase local export demand, and in turn stimulate local output and income. The importance of this third factor is likely to depend on the size of the region, which will be discussed in the next section.

We suspect that the four-equation sub-model does not fully capture this third effect because it does not explicitly allow for the induced demand for 
local goods and services arising from the new public sector employment. Consequently, the "simple" AIE derived from it may be biased downward. The most direct indicator of this induced demand is the change in retail sales within the region. Equation (14), which explains retail sales, thus was added to the previous four equations. Results of a simultaneous estimation of the parameters of this five-equation sub-model are shown in the bottom half of Table 1. The coefficients of this sub-model can be used to derive a more complete AIE, which more realistically measures the effect of changes in the size of the public sector workforce.

Regional sales are largely explained by regional income, consistent with Keynesian consumption theory. An anomaly is the negative sign of PI in equation (14). This may have resulted from the high correlation between WI and PI over SMSA's that causes sufficient multicollinearity to reduce the reliability of one or both income coefficients. The coefficient of the median age of residents, AGE, indicates that older households in the region tend to spend a larger fraction of incomes locally than do younger households. Retail sales are negatively correlated with the percentage of workers residing within an SMSA who commute to jobs outside their home SMSA, $\mathrm{D}^{(\mathrm{c})}$. These workers are likely to spend part of their incomes in other areas, reducing the benefits captured by their residential area.

The AIE estimated from the five-equation sub-model is (4.041) (7.231) $=29.220$. This means that each additional public sector employee, if retained in the workforce long enough, generates direct and indirect income totalling $\$ 29,220$. As expected, the effect of allowing sales to be determined endogenously is to increase the AIE. ${ }^{15}$ The difference between the two AIE's presented in this section is $\$ 11,784$, which is an estimate of the pure "induced" or "secondary" effect of public sector employment.

\section{THE AREA INCOME EFFECT: ADJUSTMENTS FOR REGION SIZE}

Regional economists have provided important evidence of the effect of region size on regional incomes. ${ }^{16}$ The significance of agglomeration economies in the theory of regional development has been stated by many writers. ${ }^{17}$ The Keynesian government expenditures multiplier (and, analogously, Keynes' earlier employment multiplier) has been shown to be inversely related to the propensity to import. ${ }^{18}$ This propensity is likely to be small in large regions that provide residents with a variety of locally produced goods and services. These large regions, therefore, should enjoy a higher AIE than smaller regions.

We examined the role of size as a determinant of the AIE by creating a dummy variable $S$, where $S=1$ for SMSA's with populations over 1 million and $S=0$ otherwise, and an interaction term $S^{(\mathbf{g})}$ equal to the product of the dummy variable and public sector employment. The interaction term was used in the total employment equation. Its coefficient measured the difference between large and small regions of the impact of marginal changes in public sector employment on total employment. The dummy variable also was used in the sales equation. ${ }^{20}$ These two variables affected the TSLS 
estimates of the paramenters of the wage income and total employment equations that were used to calculate the AIE. These parameter estimates are shown in Table 2.

For the 4-equation model (exogenous retail sales), the AIE for small regions is the product of the coefficients of government employment, in the total employment equation, and of total employment in the wage income equation. This AIE is $(7.221)(0.935)=6.751$. For large regions the AIE is $(7.221)(1.227+0.935)=15.638$. An additional non-federal government employee, on average, contributes more than twice as much to wage income in large regions as in small ones.

The AIE's calculated from parameter estimates of the five-equation sub-model are larger, as we would expect when allowing for endogenous private sector activity. For small regions each government worker adds about $\$ 11,450=(7.233)$ (1.583) to wage income, while each government worker employed in large regions adds an average of $\$ 24,469=(7.233)$ $(1.800+1.583)$ to wage income. Comparing these figures with the two AIE estimates given above, we estimate the induced income effect to be about $\$ 4,700$ in small regions and about $\$ 8,800$ in large ones. This comparison of income effects in small and large regions underscores the importance of agglomeration economies, and import substitution, as determinants of the impact public sector employment has on economic activity.

This last pair of AIE estimates, $\$ 11,450$ and $\$ 24,469$, constitutes our

TABLE 2

TSLS ESTIMATES OF WAGE INCOME AND EMPLOYMENT EQUATIONS, WITH SIZE INDICATORS

\begin{tabular}{|c|}
\hline Preliminary Model \\
\hline $\begin{array}{c}\mathrm{WI}=-867.035+7.221 \times 10^{-3} \mathrm{EMP}+52.827 \mathrm{ED}+47.383 \text { UNEMP } \\
{[2.59] \quad[176.54]} \\
{[1.94]}\end{array}$ \\
\hline 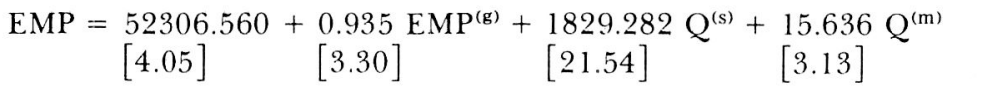 \\
\hline $\begin{array}{l}-15293.5(\mathrm{~W} / \mathrm{P})^{(\mathrm{m})}+1.227 \mathrm{~S}^{(\mathrm{g})} \\
{[3.67] \quad[4.82]}\end{array}$ \\
\hline Full Model \\
\hline $\begin{array}{c}\mathrm{WI}=-861.019+7.233 \times 10^{-3} \mathrm{EMP}+52.051 \mathrm{ED}+47.526 \mathrm{UNEMP} \\
{[2.57] \quad[176.93]} \\
{[1.92]}\end{array}$ \\
\hline $\begin{aligned} \mathrm{EMP}= & 65380.85+1.583 \mathrm{EMP}^{(\mathrm{g})}+1126.30 \mathrm{Q}^{(\mathrm{s})}+49.032 \mathrm{Q}^{(\mathrm{m})} \\
& {[4.87] \quad[5.70] \quad[9.33] }\end{aligned}$ \\
\hline $\begin{array}{l}-16696.500(\mathrm{~W} / \mathrm{P})^{(\mathrm{m})}+1.800 \mathrm{~S}^{(\mathrm{g})} \\
{[3.88] \quad[6.60]}\end{array}$ \\
\hline
\end{tabular}


best estimates of the area income effect. These figures are smaller than the ones presented in the preceding section. However, the significance of the size variables in the latest version of the model's structural equations suggests that this version is a more appropriate specification.

These estimates of the AIE's of public employment have some important implications for public sector budget policy. First, increments in public services, as represented by public sector employment, stimulate regional wage income and may be useful as part of a regional economic development program. It should be noted that the AIE measures the net change in income arising from both the positive impact of government employment, and the negative effect of the reduction in disposable income due to the associated increase in public revenues needed to finance the new government services. Second, our results suggest that in an era when there is considerable political interest in reducing budgets of governments, budget planners should carefully consider the effects of changes in the level of public services on regional income. A positive AIE indicates that any reduction in government employment will lead to a net decrease in aggregate regional income. However, the results of section IV suggest there is substantial variation in AIE's among regions. Demographically small regions, having a smaller AIE coefficient, will experience comparatively small changes in income from changes in public employment. Aside from area size, the income effect is likely to vary also with the extent to which a region's public employment is financed through the receipt of intergovernmental transfers. Regions whose governments derive relatively small proportions of their revenues from transfers will have smaller positive AIE's when public services are expanded, and are likely to experience comparatively small losses in regional income when public employment is cut.

\section{FOOTNOTES}

1. William C. Lewis, "Public Investment Impacts and Regional Economic Growth," WATER RESOURCES RESEARCH 4 (1973) 4:851-860.

2. U.S. Bureau of the Census, COUNTY AND CITY DATA BOOK 1972, Washington: U.S. Government Pringing Office, 1975

3. Government programs financed by a higher level of government are sometimes characterized as having a "Santa Claus effect."

4. Reporting dates for census data provided in the COUNTY AND CITY DATA BOOK on government employment cover a three year period. Federal employment is reported for 1970, whereas comparable local government employment is reported for 1967. No specific estimates are given for state employment. In addition, there'exist differences due to seasonal variations.

5. See, for example, David Segal, "Are There Returns to Scale in City Size?," REVIEW OF ECONOMICS AND STATISTICS, vol. 53, (August, 1976), pp. 339-50; and Burkhard von Rabenan and Donald A Hanson, "The Provision of Public Goods in a Growing Urban Economy," REGIONAL SCIENCE AND URBAN ECONOMICS, vol. 9, (1979), pp. 1-20.
6. F. Gerard Adams, Carl G. Brookings, and Norman J. Glickman, "On the Specification and Simulation of a Regional Econometric Model: A Model of Mississippi," REVIEW OF ECONOMICS AND STATISTICS, vol. 52 (August, 1975), no. 3, pp. 286-298.

7. See, for example, Ronald G. Ehrenberg, "The Demand for State and Local Government Employees," AMERICAN ECONOMIC REVIEW, vol. 63 (June, 1973), no. 3, pp. 366-79; Thomas E. Borcherding and Robert T. Deacon, "The Demand for the Services of Non-Federal Governments," AMERICAN ECONOMIC REVIEW, vol. 62 (December, 1972). no. 5, pp. 801-901; and Robert F. Adams, "On the Variation in the Consumption of Public Services," THE REVIEW OF ECONOMICS AND STATISTICS, vol. 42 (November, 1965), no. 4, pp. 400-405.

8. This simple AIE in effect implies that the region is economically small, so that all new income results in demand for goods and services created outside the region. Local private sector output is independent of public sector employment and is exogenous to the model.

9. An SMSA is a county or group of functionally inte- 
grated contiguous counties which contains at leas one city of 50,000 inhabitants or more, or "twin cities" with a combined population of at least 50.000 .

10. The TSLS estimator allows for simultaneity among equations within a model. The first stage of the calculation consists of regressing the four or five endogenous variables in the sub-model against all of the exogenous variables and deriving conditional expected values for the endogenous variables for each SMSA. In the second stage these expected values are used as observations to derive the ordinary least squares (OLS) estimates of the structural equations (see, M. Dutta, EC.ONOMETRIC METHODS, Cincinnati, Ohio; South-Western Publishing C.o. 1975. pp. 298-309).

11. The actual sample consisted of 243 SMSA's because three areas with very high concentrations of federal employees were eliminated.

12. Ben-Chieh Liu, QUAIITY OF I.IFE INDIC.ATORS IN U.S. METROPOI.ITAN AREAS New York: Praeger Publishers, 1976. Tables A-5. $\mathrm{B}-5$, and $\mathrm{C}-5$.

13. Liu ifrid. estimated the ratio of personal income in each SMSA from wages and salaries. Total personal income was multiplied by this ratio to derive WI. The difference between personal income and WI was used to indicate property income (PI) specified in equations (11) and (12).

14. Michael K. Evans, MACROECONOMIC ACTIVITY: THEORY FORECASTING AND CONTROL. NEW York: Harper and Row, 1969, pp. 567-68.
15. We have no information on the mean cost per employee in the public sector. However, the final AIE figure could be used to derive government expenditure multipliers that are consistent with long-run multipliers developed by others. For example, if the mean cost was $\$ 10,000$ (which is reasonable for 1972 wages and prices)-for salary, fringe benefits, and supporting resources-the conventional government expenditures multiplier would be just under 3.00 .

16. See William Alonso, "The Economics of Size," PAPERS OF THE REGIONAL SCIENCE ASSOCIATION, vol. 26 (1970), pp. 67-83; von Rabenau and Hanson, op. cit, and Segal, op. cit.

17. See, for example, Edwin von Böventer, "Regional Growth Theory," URBAN STUDIES, vol. 12 (1975), pp. 1-29; and J. V. Henderson, "The Size and Types of Cities," AMERICAN ECONOMIC REVIEW, vol. 64 (September, 1974) pp. 640-56.

18. Evans, op. cit., pp. 542-47.

19. Import substitution plays a major role in growth pole theory. See, for example, Walter Isard, AN INTRODUCTION TO REGIONAL SCIENCE, Englewood Cliffs, New Jersey: Prentice Hall, 1975 , pp. 380-83.

20. Neter and Wasserman. (pp. 160-66) explain the rationale and application of interaction analysis based on dummy variables. See John Neter and William Wasserman, APPI.IED LINEAR STATISTICAL MODEL.S. Homewood. Illinois: Richard D. Irwin, 1974, pp. 160-166. 